Eur. J. Clin. Chem. Clin. Biochem.

Vol. 32, 1994, pp. 435-440

(C) 1994 Walter de Gruyter \& Co.

Berlin · New York

\title{
The Influence of Glycation on the Peroxidase Activity of Haemoglobin
}

\author{
By U. Y. Khoo ${ }^{1}$, D. J. Newman ${ }^{1}$, W. K. Miller ${ }^{2}$ and C. P. Price ${ }^{1}$ \\ 1 Department of Clinical Biochemistry, The London Hospital Medical College, London, U.K. \\ ${ }^{2}$ E. I. DuPont de Nemours \& Co., Glasgow Research Laboratories, Wilmington, Delaware, U.S.A.
}

(Received July 5, 1993/March 7, 1994)

Summary: The peroxidase activity of haemoglobin A was characterized for non-glycated and glycated haemoglobin $\left(\mathrm{HbA}_{1}\right)$ within the $\mathrm{pH}$ range 4.5 to 6.0 , by measuring the rate of oxidation of 5-aminosalicylic acid following the degradation of $\mathrm{H}_{2} \mathrm{O}_{2}$. Glycation was found to significantly lower the $\mathrm{pH}$ activity of haemoglobin peroxidase throughout the $\mathrm{pH}$ range. However, in the presence of $100 \mathrm{mmol} / 1$ sorbitol the $\mathrm{pH}$ activity profile of glycated haemoglobin was significantly elevated whilst that of non-glycated haemoglobin remained unchanged.

\section{Introduction}

Glycated haemoglobin, collectively known as $\mathrm{HbA}_{1}$, is the product of the covalent binding of sugars to $\alpha$ - or $\varepsilon$ amino groups of the major haemoglobin species, $\mathrm{HbA}_{0}$ (for reviews see Peacock, (1); Furth, (2)). The discovery of glycated haemoglobin aroused much interest because certain species of $\mathrm{HbA}_{1}$ were found to be elevated in humans and animals with diabetes mellitus (3-6). Although there is speculation that non-enzymatic glycation, of long-lived proteins is responsible for the development of chronic diabetic complications, the glycation of haemoglobin is in itself believed to be benign (7-9). The concentration of glycated haemoglobin has proved to be a useful index of long-term blood glucose control since it is not affected by short-term fluctuations in blood sugar, thus reflecting the glucose concentration over the preceding 12 weeks $(10-12)$ or the life of the erythrocyte.

The major sites of non-enzymatic glycation of haemoglobin in vivo, in order of prevalence, are the $\beta$-Val-1, $\beta$-Lys-66, $\alpha$-Lys-61, $\beta$-Lys-17 and $\alpha$-Val-1 (13). The most prevalent species of glycated haemoglobin, known as $\mathrm{HbA}_{1 \mathrm{c}}$, is the result of glucose binding to the $\beta$-Val1 , a site also involved with the binding of glycerate-2,3bisphosphate, $\mathrm{CO}_{2}$ and hydrogen ions ((14-15).

$\mathrm{X}$-ray diffraction studies have shown that glycerate-2,3bisphosphate forms ionic bonds with Val-1, His-2 and
-143 of both $\beta$-chains and Lys-82 of either $\beta$-chain (16). Not unexpectedly, the rate of formation of $\mathrm{HbA}_{\mathrm{Ic}}$ was found to be affected both by elevated levels of glycerate2,3 -bisphosphate and oxygen tension $(15,17)$. There is also some evidence that glycation increases the oxygen affinity of haemoglobin (18).

Although it is unlikely that glycation has any important physiological consequences on the respiratory function of haemoglobin (19), the blocking of the $\alpha$-amino position of the $\beta$-chain gives rise to significant biophysical and biochemical modifications of the haemoglobin molecule; early detection of $\mathrm{HbA}_{1 \mathrm{c}}$ was itself a result of altered electrophoretic mobility (3). Some of these modifications are clinically useful and have been utilised in the development of analytical methods for the separation of the glycated from the non-glycated forms. For instance, the formation of the ketoamine link between the glucose moiety and the haemoglobin molecule lowers the $\mathrm{pK}_{\mathrm{a}}$ of the amino groups involved (20). This allows the separation, by cation exchange chromatography, of $\mathrm{HbA}_{\mathrm{Ic}}$ at neutral $\mathrm{pH}$ and the partial separation of the haemoglobin species with glucose attached to the $\mathrm{NH}_{2}$-terminus of the $\alpha$-chain (21). Glycation also alters the $\mathrm{pl}$ of haemoglobin, though only by $0.0001 \mathrm{pH}$ units making conventional electrophoretic techniques unsuitable (20). Nonetheless, separations have been achieved by techniques which rely on $\mathrm{HbA}_{0}$ being more posi- 
tively charged than $\mathrm{HbA}_{1}$, thus enabling the retardation of the non-glycated species on a negatively charged matrix (11).

Haemoglobin, by virtue of its iron(III) protoporphyrin IX group also has the catalytic features of other members of the haemoprotein family, such as horse radish peroxidase and cytochrome oxidase. In general, peroxidase enzymes are capable of reducing $\mathrm{H}_{2} \mathrm{O}_{2}$ to form water, by 2 one electron steps or one 2 electron step (22). Most of the studies on the peroxidase activity of globins have been carried out using myoglobin, which forms an oxidized intermediate considered to be a model for other peroxidase compounds (23). X-ray absorption spectroscopy has revealed that this intermediate is not identical with Compound I or II of the horse radish peroxidase reaction, although it has some structural features in common. Clearly structural variances underlie the fundamental differences between globin and non-globin haem enzymes.

In 1939, Polonovski \& Jayle (24) observed that the $\mathrm{pH}$ optimum for the peroxidase activity of free haemoglobin is shifted to a more acidic $\mathrm{pH}$ in the presence of haptoglobin. This was confirmed by Connell \& Smithies (25) who also found that the peroxidase activity of the haemoglobin haptoglobin complex had a maximum activity at $\mathrm{pH}$ 4. In this paper, we report that the binding of a sugar moiety to haemoglobin significantly lowers the peroxidase activity of haemoglobin in the $\mathrm{pH}$ range 4.5 to 6 and that the presence of $100 \mathrm{mmol} / \mathrm{l}$ sorbitol selectively increases the peroxidase activity of glycated haemoglobin.

\section{Materials and Methods}

Unless otherwise stated, all chemicals were Analar grade from Sigma Chemical Company Ltd. Poole, U.K.

\section{Preparation of haemoglobin}

Blood samples were obtained from healthy volunteers by venepuncture. Red cells collected in vials containing EDTA were washed with 5 volumes of $9 \mathrm{~g} / 1$ saline and haemolyzed with 1 volume of distilled water. Cell debris was sedimented by centrifugation at $30000 \mathrm{~g}$ in a Sorvall RC-5B refrigerated centrifuge (DuPont, Stevenage, U.K.) and the haemolysate harvested and stored at $-20^{\circ} \mathrm{C}$ until use. Individual haemolysates were prepared and used separately as follows.

\section{Affinity chromatography}

A $10 \mathrm{~g}$ quantity of $m$-aminophenyl boronic acid Sepharose-linked beads (Sigma) was immersed for 30 minutes in $50 \mathrm{mmol} / \mathrm{l}$ $\mathrm{Na}_{2} \mathrm{HPO}_{4}$ containing $154 \mathrm{mmol} / 1 \mathrm{NaCl}$ and $100 \mathrm{mmol} / \mathrm{l}$ sorbitol, $\mathrm{pH}$ 9.2. A $4 \mathrm{ml}$ column was packed with the beads, washed with the same buffer and then equilibrated in this buffer without sorbitol (columns can be used at least 3 times with regeneration between usage with $100 \mathrm{mmol} / \mathrm{l}$ sodium acetate buffer $\mathrm{pH} \mathrm{5.0).}$
A $2 \mathrm{ml}$ aliquot of haemolysate containing $250 \mu \mathrm{l}$ of $500 \mathrm{mmol} / \mathrm{]}$ $\mathrm{Na}_{2} \mathrm{HPO}_{4}$ was pumped into the column and 20 minute fractions were collected at a flow rate of $0.25 \mathrm{ml} / \mathrm{min}$. The column was washed with equilibration buffer for $60 \mathrm{~min}$ before the adsorbed (glycated) fraction was eluted with $100 \mathrm{mmol} / \mathrm{l}$ sorbitol-containing buffer. The non-adsorbed fractions were pooled and reapplied to the column until no glycated haemoglobin was desorbed. The separated haemoglobin fractions were concentrated, and excess sorbitol from the glycated haemoglobin pool was removed, by ultrafiltration (M8010 stirred cell; Millipore UK Ltd.). The haemoglobin concentration was measured spectrophotometrically at 405 $\mathrm{nm}$ and a standard curve drawn from serial dilutions of a haemolysate pool whose initial concentration, measured by Drabkin's me= thod, was $122.2 \mathrm{~g} / \mathrm{l}$. The samples collected were stored at $4^{\circ} \mathrm{C}$ for a period not exceeding 10 days until use. Stock haemoglobin solutions were diluted, with $50 \mathrm{mmol} / 1$ phosphate buffer $\mathrm{pH} 7.4$ containing $154 \mathrm{mmol} / \mathrm{l} \mathrm{NaCl}$, to the final assay concentration immediately before carrying out an assay.

\section{Reagents}

\section{Hydrogen peroxide}

A solution of approximately $10 \mathrm{mmol} / 1 \mathrm{H}_{2} \mathrm{O}_{2}$ was prepared immediately before use by dilution of the stock solution (approximately $8.3 \mathrm{~mol} / 1 \mathrm{H}_{2} \mathrm{O}_{2}$ ) in distilled water.

\section{Chromogen reagent}

The chromogen 5-aminosalicylic acid was chosen as it appeared from initial experiments to be reasonably stable, not suffering problems associated with light sensitivity. A $3 \mathrm{mmol} / \mathrm{l}$ buffered solution of 5-aminosalicylic and was prepared by dissolving a $10 \mathrm{mg}$ tablet (Sigma) in $22 \mathrm{ml}$ of citrate phosphate buffer $(100 \mathrm{mmol} / \mathrm{l}$ citric acid, $200 \mathrm{mmol} / 1 \mathrm{Na}_{2} \mathrm{HPO}_{4}$ ) and made up immediately before use at pH's 4.50 to 6.00 at $0.5 \mathrm{pH}$ intervals. The 5 -aminosalicylic acid reagent was stable for up to 24 hours when stored at $4^{\circ} \mathrm{C}$, beyond which time the rate of colour production per mol of chromogen was found to be decreased (due to auto-oxidation).

\section{Substrate chromogen reagent}

Immediately prior to use the $10 \mathrm{mmol} / 1 \mathrm{H}_{2} \mathrm{O}_{2}$ was mixed with the buffered 5-aminosalicylic acid in the proportion $1: 12.33$.

\section{Apparatus}

The Multistat III Plus Microcentrifugal Analyzer (Instrumentation Laboratory, Warrington, U.K.) was used to monitor substrate and enzyme assays. Analyses were performed at $30^{\circ} \mathrm{C}$ using a $405 \mathrm{~nm}$ interference filter.

\section{Assay procedure for peroxidase activity}

A $30 \mu \mathrm{l}$ aliquot of diluted haemoglobin (equivalent to $<0.1 \mathrm{~g} / 1$ in the sample) and $230 \mu \mathrm{l}$ of freshly prepared substrate chromogen solution were dispensed into the respective compartments of the analyser rotor. The reaction was initiated by centrifugation and $a b=$ sorbance data collected between 0 and $600 \mathrm{~s}$ at $30 \mathrm{~s}$ intervals.

\section{Assay procedure for measurement of extinction coefficient}

For the determination of the extinction coefficient of the oxidised chromogen, the concentration of diluted haemoglobin in the $30 \mu l$ aliquot was increased to $>1.0 \mathrm{~g} / \mathrm{A}$ and the reaction monitored for $20 \mathrm{~min}$. 


\section{Statistical analyses}

Paired and unpaired 2-tailed Students t-tests were conducted using the Statworks ${ }^{\mathrm{TM}}$ package (Cricket Software, 3508 Market Street, Suite 206, Philadelphia, PA 19104) on a Macintosh SE computer.

\section{Results}

\section{Variation of extinction coefficient with $\mathrm{pH}$}

The absorbance change for a given amount of $\mathrm{H}_{2} \mathrm{O}_{2}$ was determined in the presence of an excess of peroxidase ( $\mathrm{n}=10$ overall) at each $\mathrm{pH}$ using four different blood samples. The data are summarized in figure 1 (a) and (b), and show that the colour produced was unstable at the lower pH's and consequently there is a difference in the measured absorbance change at different $\mathrm{pH}$ 's resulting in differences in the apparent extinction coefficients at each $\mathrm{pH}$.

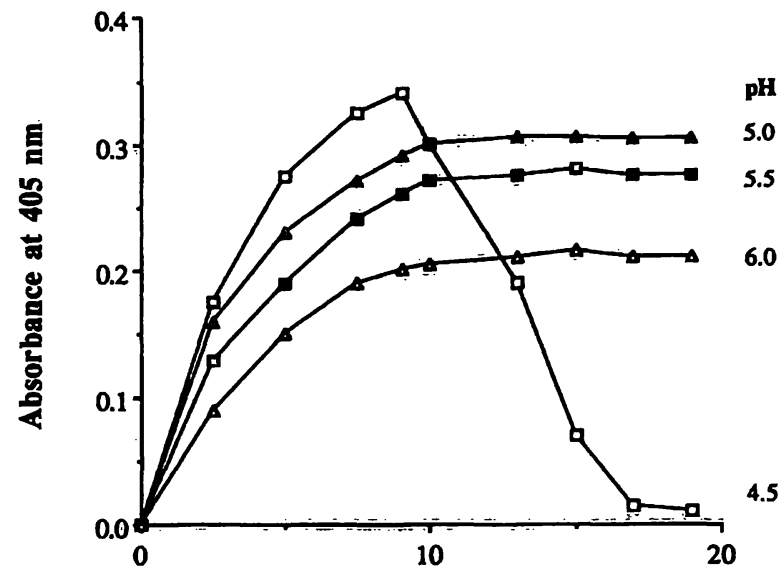

a)

Time [min]

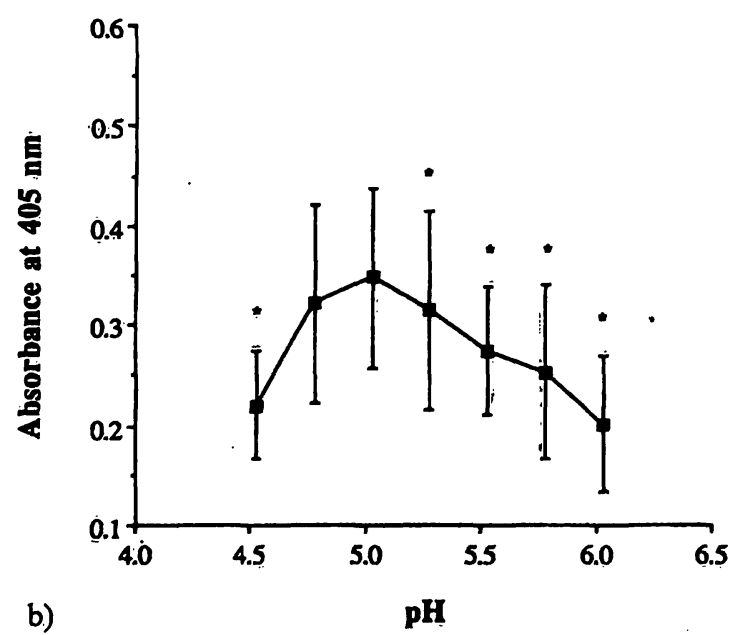

b)

1 Fig. 1 pH dependence of the reaction:

a) rate of colour development at reaction $\mathrm{pH} 4.5$ (ㅁ) 5.0 (A), 5.5

(a) and 6.0 $(\Delta)$ for a constant $\mathrm{H}_{2} \mathrm{O}_{2}$ concentration;

b) mean maximum absorbance changes $( \pm S D)$ at different reaction $\mathrm{pH},{ }^{*} \mathrm{p}<0.05$ vs $\mathrm{pH}$ 5.0.

\section{Effect of glycation on peroxidase activity}

Glycated and non-glycated haemoglobin were separated by affinity chromatography and concentrated by ultrafiltration. In each case the haemoglobin solution was diluted to a concentration between 0.1 and $0.3 \mathrm{~g} / \mathrm{l}$ with phosphate buffered saline ( $\mathrm{pH} \mathrm{7.4)} \mathrm{and} \mathrm{the} \mathrm{peroxidase}$ activity determined as described earlier with the activity expressed in relation to the given level of haemoglobin. Blood samples were obtained from four donors (analysed separately) and a total of ten measurements were made at each reaction $\mathrm{pH}$. The data are shown in figure 2. Figure 3 shows the same $\mathrm{pH}$ profile in activity but expressed as initial rates of reaction rather than specific activity, as this is the manner used to express such data in previous studies.

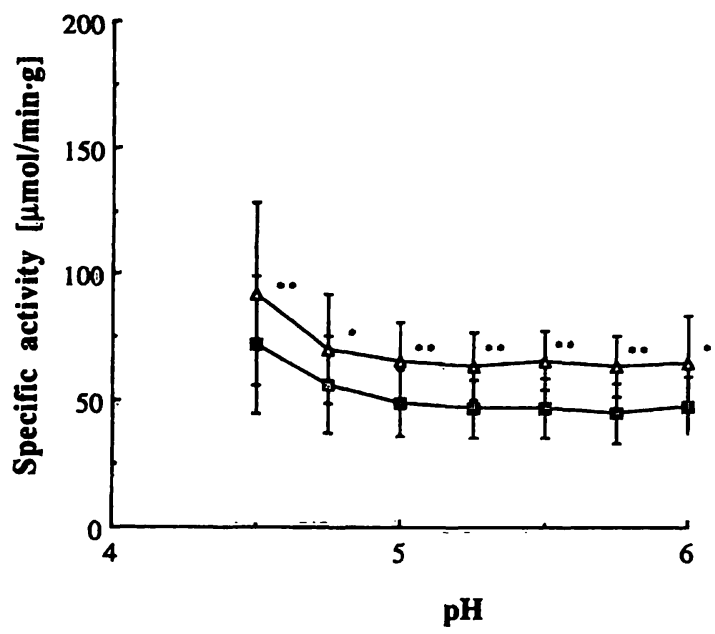

Fig. 2 The relation of mean peroxidase specific activity ( \pm SD) for glycated (D) and non-glycated $(\Delta)$ haemoglobin to $\mathrm{pH}, * \mathrm{P}<0.001 * * \mathrm{P}<0.05$.

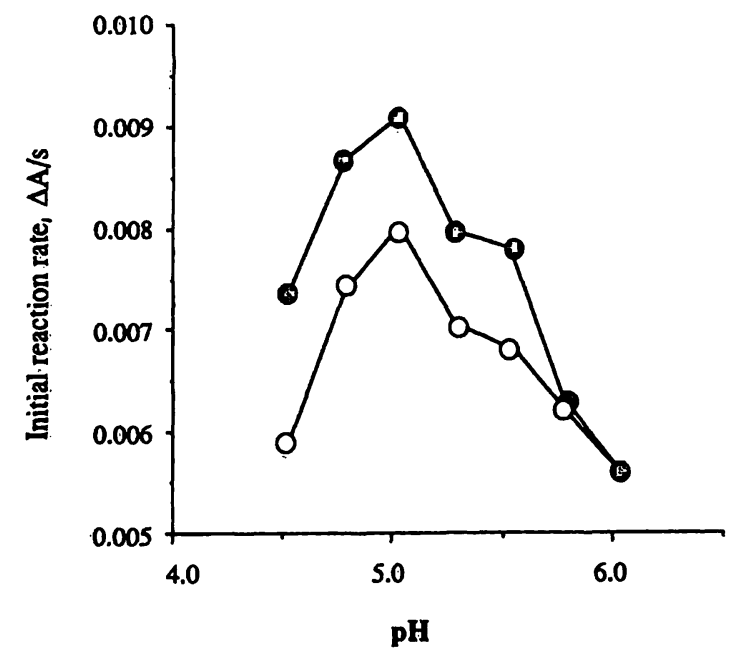

Fig. 3 The relation between apparent peroxidase activity for glycated $(\bullet)$ and non-glycated $(0)$ haemoglobin with $\mathrm{pH}$. In this cxperiment the amount of glycated haemoglobin used was greater than that for non-glycated $(0.17 \mathrm{~g} / \mathrm{l}$ against $0.13 \mathrm{~g} / \mathrm{l})$ accounting for the greater absorbance change of the former. 
Effect of sorbitol on peroxidase activity of haemoglobin fractions

In order to establish whether sorbitol had any influence on the peroxidase activity of haemoglobin, the sorbitol employed to elute the glycated haemoglobin was subsequently removed from the eluate by repeated ultrafiltration with phosphate buffered saline ( $\mathrm{pH}$ 7.4). The glycated and non-glycated haemoglobin fractions were then diluted with a phosphate buffered saline buffer containing $100 \mathrm{mmol} / \mathrm{l}$ sorbitol and incubated at room temperature for 2 hours. Duplicate measurements were then made of the peroxidase activity of both haemoglobin fractions from four blood donors. The data are shown in figure 4 .

\section{Discussion}

The glycation of haemoglobin has been an interesting model for the study of chemical and allosteric properties

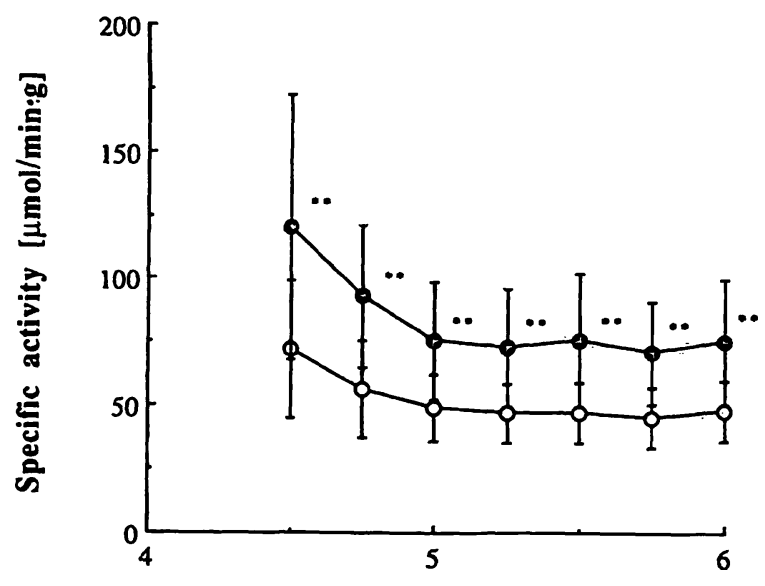

a) pH

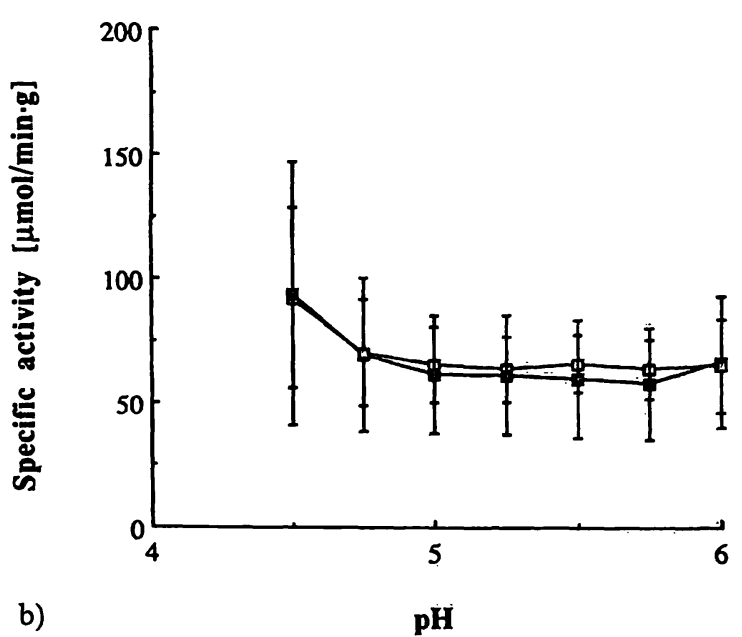

Fig. 4 The relation of mean peroxidase specific activity ( $\pm S D$ ) of

a) glycated (circle) and

b) non-glycated (square) haemoglobin in the presence (closed symbol) and absence (open symbol) of sorbitol $* * P<0.05$. of the haemoglobin molecule. The $\alpha$-amino group of valine of the $\beta$-chain to which glucose binds to form $\mathrm{HbA}_{\mathrm{lc}}$, lies in the central cleft of the haemoglobin molecule adjacent to its 2-fold axis of symmetry, which is also directly involved with the binding of glycerate-2,3bisphosphate, $\mathrm{CO}_{2}$ and hydrogen ions $(14,16,26)$. The binding of oxygen causes a series of conformational changes throughout the haemoglobin molecule including an alteration in the distance between the $2 \alpha$-amino groups of the $\beta$-chain which decreases from 2 to $1 \mathrm{~nm}$ (14). This change in conformation is critical to the functional binding of the glycerate-2,3-bisphosphate molecule, which has a lower affinity for the oxygenated form of haemoglobin. It is therefore not unreasonable to expect that the binding of glucose will block the interaction of haemoglobin with glycerate-2,3-bisphosphate (15). However the results of studies attempting to elucidate this have been contradictory $(15,17,18)$. It may be that glycerate-2,3-bisphosphate works by decreasing the effective positive charge on the amino-terminus thereby raising its reactivity with glucose, or it may be causing a conformational shift that results in improved steric factors (17). Deoxygenated haemoglobin was found to be glycated twice is rapidly as oxygenated haemoglobin, at the same glucose concentration; moreover, the effect of glycerate-2,3-bisphosphate on $\mathrm{HbA}_{\mathrm{lc}}$ formation was more marked with deoxy- rather than with oxyhaemoglobin. This implies that the conformational state of haemoglobin may play an important role in the formation of $\mathrm{HbA}_{1 \mathrm{c}}$. If glycation is associated with a change in the quarternary structure of haemoglobin, it follows that the enzymic properties of the haemoglobin molecule may also be modified.

Since the early part of this century, the peroxidase activity of haemoglobin has been employed for the detection of faecal occult blood, and in more recent times, for the estimation of haptoglobin binding capacity and in the detection of lipid hydroperoxidase $(27,28)$. Most previous studies on haemoglobin peroxidase activity have been concerned with measuring the activity of the haemoglobin-haptoglobin complex $(24,25,29,30)$. The formation of the haemoglobin-haptoglobin complex is thought to stabilize the protein against acid denaturation (31), thus moving the $\mathrm{pH}$ optimum of haemoglobin peroxidase activity to a lower $\mathrm{pH}$ value. There have not been any previous investigations on the effect of the binding of other endogenous circulating molecules on haemoglobin peroxidase activity. In this study, it was found that the glycation of haemoglobin markedly affects the peroxidase activity of the haem enzyme and there is a significant difference in the calculated specific activity of glycated compared to non-glycated haemoglobin across the $\mathrm{pH} 4.5$ to 6.0 , figure 2 . 
The peroxidase activity $\mathrm{pH}$ profile drawn from this study is notably different from the profiles found by previous investigators. In these earlier studies $(25,29-31)$, enzyme activity was expressed by the initial (linear) rate of reaction. A quantitative comparison with the rate of change of absorbance in the present study is impossible firstly, because guaiacol had been used in the earlier studies as the reducing substrate, having been selected because the authors were concerned with the peroxidase activity of the haemoglobin haptoglobin complex and guaiacol is a powerful inhibitor of the peroxidase activity of free haemoglobin at concentrations exceeding $2.5 \mathrm{mmol} / \mathrm{l}$. Moreover, the buffer system used in earlier studies also differed from that used here, and enzyme reaction rates vary with buffer type (unpublished observations). However, the main reason for the differences in the $\mathrm{pH}$ activity profile is due to the fact that the extinction coefficient of the oxidised chromogen varies with $\mathrm{pH}$. When the profile is redrawn employing the initial rate of increase in absorbance, the profile is similar to that demonstrated by other workers (see fig. 3). In fact neither profile is necessarily a totally accurate reflection of the relationship because the oxidised chromogen was shown to be unstable at low pH's thereby giving an underestimate of the extinction coefficient and consequently an overestimate of the activity.

A further novel finding in this study was the effect of the polyhydroxyalcohol, sorbitol, which increased the peroxidase activity of glycated haemoglobin, without significantly altering that of non-glycated haemoglobin (see fig. 4). Polyhydroxyl alcohols are known to stabilize protein structure and sorbitol may well be affecting the difference in activity in such a manner. In the affinity separation of glycated haemoglobin, sorbitol acted by reversibly binding the cis-diol group on the glucose moiety. Sorbitol does not contain a ketone group, so it is highly unlikely that covalent binding can occur to the haemoglobin molecule, as is the case with glycation. Since the activity of only glycated haemoglobin was found to be significantly altered, it is quite possible that the action of sorbitol was via cis-diol interaction with the glucose group on glycated haemoglobin. As the eluting agent in the affinity separation of the glycated fraction, the cis-diol group of sorbitol is critical. The question of whether this factor is responsible for the observed elevation in peroxidase activity may be examined by using carbohydrates with a different configuration, for instance xylose and $L$-sorbose which lack a cis-diol group.

The findings described in this paper indicate that glycation has a significant effect on the peroxidase activity of haemoglobin. However, it is not possible to determine if this change has any influence over the physiological activity of the molecule in relation to its peroxidase activity.

\section{Acknowledgement}

We thank Dr. M. F. Perutz for invaluable discussions. This work was supported by a grant from EI Du Pont de Nemours International.

\section{References}

1. Peacock, I. (1984) Glycosylated haemoglobin: Measurement and clinical use. J. Clin. Path. 37, 841-851.

2. Furth, A. J. (1988) Methods for assaying non enzymatic glycosylation. Anal. Biochem. 175, 347-360.

3. Rahbar, S. (1968) An abnormal haemoglobin in red cells of diabetics. Clin. Chim. Acta 22, 296-298.

4. Trivelli, L. A., Ranney, H. M. \& Lai, H. T. (1971) Haemoglobin components in patients with diabetes mellitus. N. Engl. J. Med. 284, 353-357.

5. Koenig, R. J. \& Cerami, A. (1975) Synthesis of haemoglobin $A_{1 c}$ in normal and diabetic mice: Potential model of basement membrance thickening. Proc. Natl. Acad. Sci. USA 72, 3687-3696.

6. Koenig, R. J., Aranjo, D. C. \& Cerami, A. (1976) Increased haemoglobin $A_{1 c}$ in diabetic mice. Diabetes 25, 1-10.

7. Brownlee, M., Vlassara, H. \& Cerami, A. (1984) Nonenzymatic glycosylation and the pathogenesis of diabetic complications. Ann. Int. Med. 101, 527-537.

8. Koenig, R. J. \& Cerami, A. (1980) Haemoglobin $A_{1 c}$ and diabetes mellitus. Ann. Rev. Med. 31, 29-34.

9. Lauritzen, T., Frost-Larsen, K., Larsen H. W. \& Deckert, T. (1983) Effect of 1 year of near-normal blood glucose levels on retinopathy in insulin-dependent diabetics. Lancet 1, 200-204.

10. Koenig, R. J., Peterson, C. M., Kilo, C., Cerami, A. \& Williamson, J. R. (1975) Haemoglobin $A_{I c}$ as an indicator of the

degree of glucose intolerance in diabetes. Diabetes 25, 230232.

11. John, W. G., Bullock, D. G. \& Mackenzie, F. (1992) Analysis of glycated haemoglobin: What is being measured? Diabetic Med. 9, 15-19.

12. Gabbay, K. H., Hasty, K., Breslow, R., Ellison, C., Bunn, H. F. \& Gallop, P. M. (1977) Glycosylated haemoglobins and longterm glucose control in diabetes mellitus. J. Clin. Endocrinol. Metab. 44, 859-864.

14. Perutz, M. F. (1970) Stereochemistry of cooperative effects in haemoglobin. Nature 228, 726-739.

15. Lowery, C. H., Lyness, S. J. \& Soeldner, J. S. (1985) The effect of haemoglobin ligands on the kinetics of human $\mathrm{HbA}_{1 \mathrm{c}}$ formation. J. Biol. Chem. 260, 11611-11618.

16. Arnone, A. (1972) X-ray diffraction study of binding of 2,3 diphosphoglycerate to human deoxyhaemoglobin. Nature 237 , 146-149.

17. Smith, R. J., Koenig, R. J., Binnerts, A., Soeldner, J. S. \& Aoki, T. T. (1982) Regulation of haemoglobin $A_{1 c}$ formation in human erythrocytes in vitro. J. Clin. Invest. $69,1164-1168$.

18. McDonald, M. J., Bleichmean, M., Noble, R. W. \& Bunn, H. F. (1979) Functional properties of the glucosylated minor components of human adult haemoglobin. J. Biol. Chem. 254, 7.02-7.07. 
19. Bunn, H. F., Gabbay, K. H. \& Gallop, P. M. (1978) The glycosylation of haemoglobin: Relevance to diabetes mellitus. Science 200, 21-27.

20. Garner, M. H., Bogardt, R. A. Jr. \& Gurd, F. R. N. (1976) Determination of the $\mathrm{pK}_{\mathrm{a}}$ values for the $\alpha$-amino groups of human haemoglobin. J. Biol. Chem. 250, 4398-4403.

21. Bunn, H. F., Shapiro, R., McManus, M., Garrick, L., McDonald, M. J., Gallop, P. M. \& Gabby, K. H. (1979) Structural heterogeneity of human $\mathrm{HbA}_{1}$ due to nonenzymatic glycosylation. J. Biol. Chem. 254, 3892-3898.

22. Chance, M., Powers, L., Kumar, C. \& Chance, B. (1986) Xray absorption studies of myoglobin peroxide reveal functional differences between globin and heme enzymes. Biochemistry $25,1259-1265$.

23. King, N. K. \& Winfield, M. E. (1963) The mechanism of metmyoglobin oxidation. J. Biol. Chem. 238, 1529-1528.

24. Polonovski, M. \& Jayle, M. (1938) Existance dans le plasma sanguin d'une substance activant l'action peroxydasique de l'hemoglobine. C. R. C. Soc. Biol. 128, 457-460.

25. Connell, G. E. \& Smithies, O. (1959) Human haptoglobins: Estimation and purification. Biochem. J. 72, 115-117.

26. Kilmartin, J. V. \& Rossi-Bernardi, L. (1973) Interaction of hemoglobin with $\mathrm{H}^{+}, \mathrm{CO}_{2}$ and organic phosphates. Physiol. Rev. 53, 836-890.
27. Siperstein, M. D., Forster, D. W., Knowles, H. C. Jr., Levine, R., Madison, L. \& Roth, J. (1977) Control of blood glucose and diabetic vascular disease. N. Engl. J. Med. 295, 10601063.

28. Shibata, S. S., Terao, J. \& Matsushitat, S. (1986) Limitations of the method using peroxidase activity of $\mathrm{Hb}$ for detecting lipid hydroperoxides. Lipid's 21, 792-795.

29. Smith, M. J. \& Beck, W. S. (1970) Peroxidase activity of haemoglobin and its subunits: Effects thereupon of haptoglobin. Biochim. Biophys. Acta 147, 324-333.

30. Kawamura, K., Kagiyama, S., Ogawa, A. \& Yanse, T. (1972) Kinetics of peroxidase activity, absorption spectra and oxygen affinity of human haemoglobin-haptoglobin I-I complexes. Biochim. Biophys. Acta 285, 22 =27.

31. Sasazuki, T., Tsunos, H. \& Nakajima, H. (1974) Interaction of human hemoglobin and haptoglobin or antihemoglobin antibody. J. Biol. Chem. 249, 2441-2446.

Dr. David J. Newman

Department of Clinical Biochemistry

The London Hospital Medical College

Turner Street

London $\mathrm{E} 12 \mathrm{AD}$

United Kingdom 